\title{
Adaptive Neuro Fuzzy Inference Based Direct Torque Control Strategy for Robust Speed Control of Induction Motor under Highly Variable Load Conditions
}

\author{
Yagya Bharti Goswami ${ }^{1}$, S. M. Deshmukh ${ }^{2}$ \\ ${ }^{1} \mathrm{M}$ Tech Scholar, Department of Electrical and Electronics Engineering, Disha Institute of Management \& Technology Raipur (C.G) \\ ${ }^{2}$ Head of Department, Department of Electrical and Electronics Engineering, Disha Institute of Management \& Technology Raipur (C.G)
}

\begin{abstract}
Among the most practical speed regulation techniques, direct torque control (DTC) is one of the simplest and excellent speed regulation strategy for induction motors via controlling of torque. The basic idea is to control, the torque and flux. Direct torque control is the first technology used for controlling the motor control variables of torque and flux. This methodology created the motor additional correct and quick torque control, high dynamic speed response and simple to control. The reference value can be calculated using the flux and torque estimated and also motor parameter. In the conventional DTC strategy, speed management of motor is performed by using PI controllers. Usually the performance of conventional PI controller, used in DTC, is found satisfactory throughout with this controller during the motor speed regulation. But the scenario of speed regulation with this controller, extremely enthusiastic about the system load. It is often found that, practically the performance of conventional PI controller based DTC strategy for the speed regulation of induction motor under highly variable load conditions is very poor. To overcome this difficulty, this paper proposed an Adaptive Neuro Fuzzy (ANFIS) controller based DTC speed regulation strategy for efficiently regulate the speed of induction motor in both the transient and steady state portions under highly variable load conditions. The basic idea is to generate an improved control performance by replacing the conventional PI controller with advance ANFIS controller. The performance of proposed controller and traditional PI controller has been incontestable by simulations using MATLAB/SIMULINK 2012(b). After the complete comparative analysis among the proposed ANFIS based DTC and conventional PI based DTC speed regulation of induction motor, it is shown that, the speed regulation capability of the proposed technique is very robust and efficient as compare to standard one below numerous load variations. In addition to this it is also found that, the proposed speed regulation strategy not only provides regulated speed in the transient and steady state, but also takes $76.0 \%$ less settling time as compare to conventional PI controller based DTC technique.
\end{abstract}

Keywords: Induction Motor, Speed Regulation, Direct Torque Control, ANFIS, MATLAB Simulink.

\section{Introduction}

Induction machines are used worldwide in many residential, commercial, industrial and utility applications. They transform electrical energy into mechanical energy. An induction motor may be part of a pump or fan, or connected to some other form of mechanical equipment such as a winder, a conveyor belt or a mixer. Induction motors have existed for years however were perpetually restricted in their application as a result of because it was difficult to control the speed of the motor. Nowadays induction motors square measure the popular selection among the economic industrial motors due to their rugged construction, the absence of brushes (which are required in most DC motors), the modern power electronics, and the ability to control the speed of the motor.

Direct Torque Control or DTC is the world's most advanced alternating current (AC) drive technology based on the of field oriented control of induction machines, published by German scientist Blaschke and Depenbrock in 1971 and1985. It is the very latest AC drive technology developed by $\mathrm{ABB}$ is set to replace traditional Pulse Width Modulation (PWM) drives of the open and closed-loop type in several applications [6].
The technique of Direct Torque Control works is control of torque and speed are directly supported the electromagnetic state of the motor, similar to Direct Current(DC) motor, but contrary to the approach within which ancient PWM drives used input frequency and voltage. DTC is the first technology to control the 'real' motor control variables of torque and flux [6]. It is more advantages such as of not requiring a feedback device that is using $\mathrm{AC}$ motor which is very rugged and inexpensive and no need external excitation.

This paper proposed an Adaptive Neuro Fuzzy (ANFIS) controller based DTC speed regulation strategy for efficiently regulate the speed of induction motor in both the transient and dynamic state portions under highly variable load conditions. The basic idea is to generate an improved control performance by replacing the conventional PI controller with advance ANFIS controller. The performance of proposed controller and conventional PI controller has been demonstrated by simulations using MATLAB/SIMULINK 2012(b).

\section{Direct torque control of induction motor}

The basic construct of the Direct torque control (DTC) methodology was planned by Takahashi and Noguchi in 1986. This methodology is a lot of utilized in dominant the 


\section{International Journal of Science and Research (IJSR) \\ ISSN (Online): 2319-7064 \\ Index Copernicus Value (2013): 6.14 | Impact Factor (2014): 5.611}

induction motor as a result of it's thought of a straight forward and strong methodology. The ability electrical converter operational control is a vital key during this methodology and trendy power natural philosophy has created this value effective also. The easy objective is to manage two quantities that are the stator flux vector and electromagnetic torque. Those quantities are directly controlled by choosing the correct inverter state with a mixture of sense, command and control feedback loops and by power electronics drive control in the inverter stage. High dynamic performance are often achieved by the stator flux as a result of the latter is near being sinusoidal. The stator EMF depends on the stator flux, that the magnitude of the EMF depends on the stator voltage. Hence, e $=\int(V s-$ rsis)dt, and therefore the torque, because the general definition, is that the vector of the stator flux and therefore the rotor flux. As a result, the magnitude of the stator flux and therefore the developed electromagnetic. Torque are often adjusted by choosing the state of the electrical converter of space vectors of the stator voltage [12]. The fundamental diagram illustration of Direct torque control of Induction motor operation is shown in Figure (1)

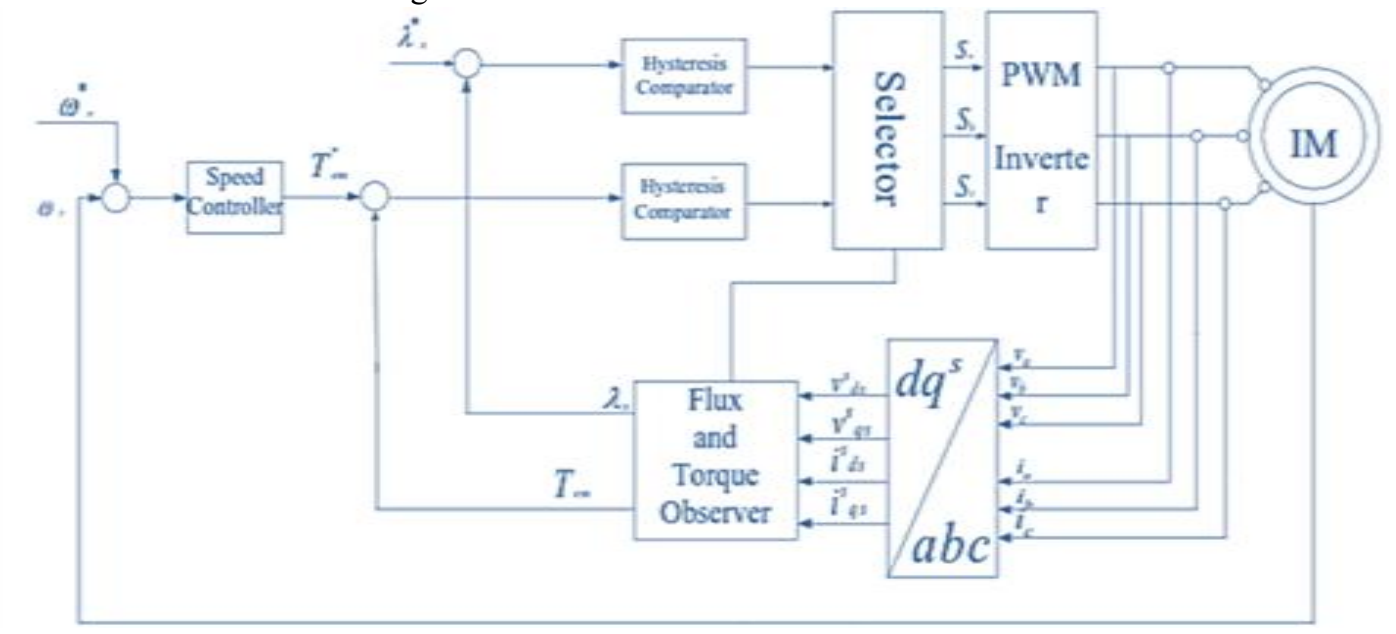

Figure 1 Block diagram of the Direct Torque Control of Induction motor

\section{Proposed ANFIS controller based DTC}

This subsection briefly describes the implementation of the proposed ANFIS controller based DTC technique for induction motor speed control along with the development of the proposed ANFIS controller. The proposed modified DTC control strategy based on ANFIS controller is shown in figure (2).

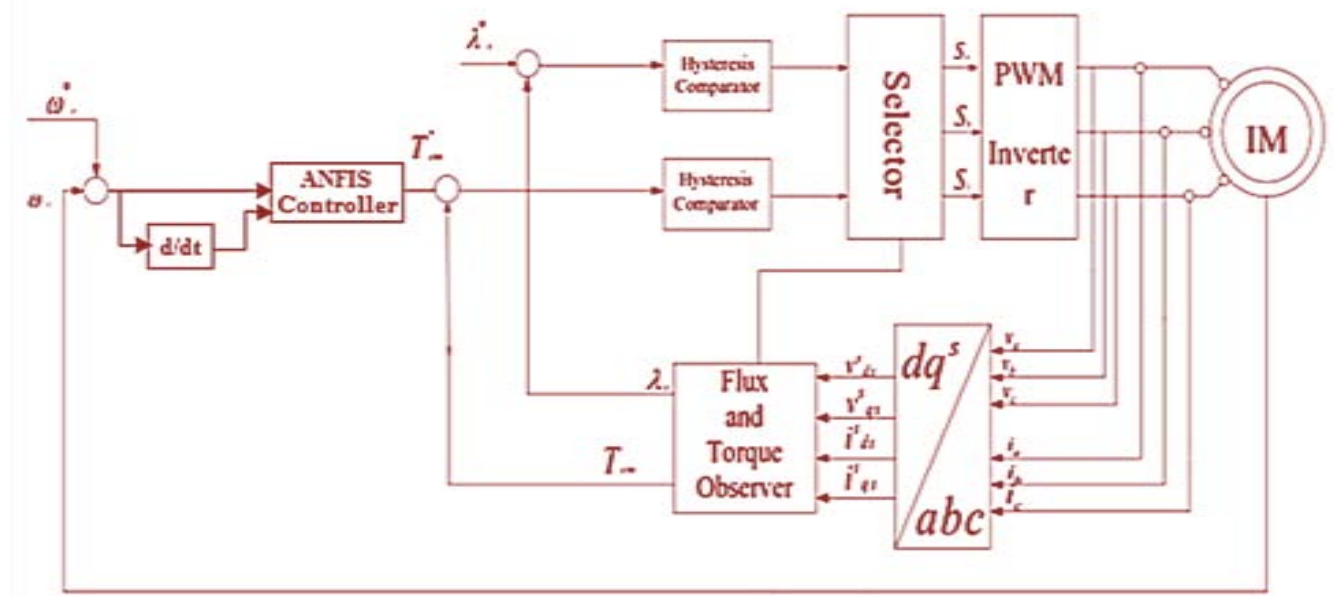

Figure 2: Block diagram of the Proposed ANFIS controller based Direct Torque Control of Induction motor.

\section{Performance evaluation of PI controller based DTC speed control under highly variable load conditions.}

A MATLAB/SIMULINK model for the proposed ANFIS based DTC is developed to present the speed control performance evaluation under highly variable load environment. The actual simulation model developed for this work is shown in figure (3) and the parameters used for the simulation of the Motor are given below:

Power $=15 \mathrm{~kW}$, Rated voltage $=400 \mathrm{~V}$, Poles $=2$, Frequency $=50 \mathrm{~Hz}, \mathrm{Rs}=0.2147, \mathrm{Rr}=0.2205, \mathrm{Ls}=\mathrm{Lr}=$ $0.000991 \mathrm{H}, \mathrm{Lm}=0.06419 \mathrm{H}, \mathrm{J}=0.102 \mathrm{~kg} \cdot \mathrm{m}^{2}, \mathrm{~F}=0.009541$ N.m.s . 


\section{International Journal of Science and Research (IJSR)

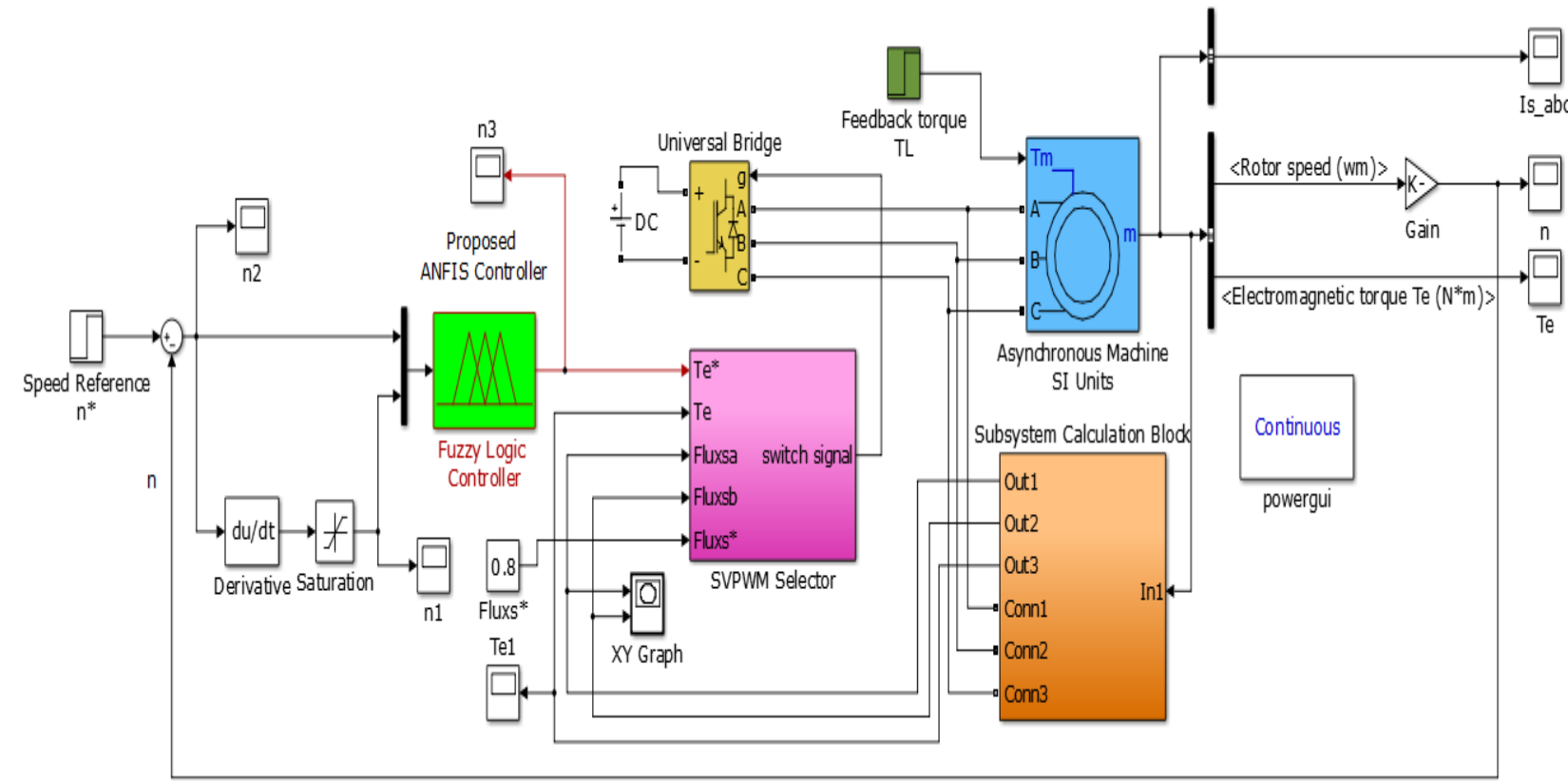

Figure 3 Actual Simulation Model Developed

For the simulation of highly variable load environment feedback torque is utilized and changed from $0 \mathrm{Nm}$ to 150 $\mathrm{Nm}$. the simulation is performed for $0.5 \mathrm{sec}$ duration along with the load change at the $0.3 \mathrm{sec}$. The $0 \mathrm{Nm}$ torque indicates no load value, while $150 \mathrm{Nm}$ torque represent very high load on the motor during the running of motor.

To present the comparative simulation results for conventional PI controller based DTC and proposed ANFIS controller based DTC under highly variable load environment, the reference speed of the motor is fixed at $1000 \mathrm{rpm}$ and load torque is changed from $0 \mathrm{Nm}$ to $150 \mathrm{Nm}$ in steps of $30 \mathrm{Nm}$. Figure (4) to figures (9), shows the speed response waveforms of induction motor at $1000 \mathrm{rpm}$ with different feedback torque values.

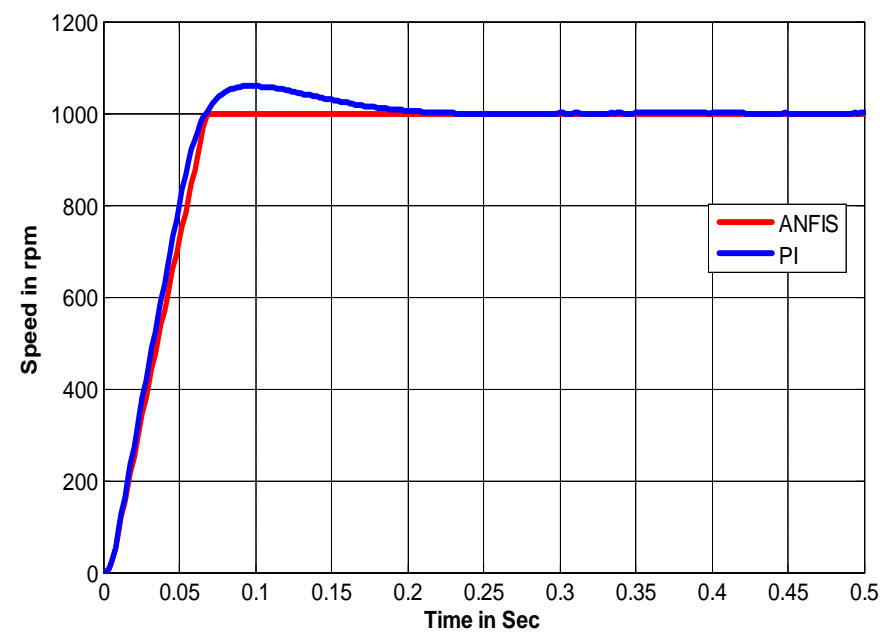

Figure 4 Comparison of speed Regulation of Induction motor using PI and ANFIS controllers based DTC for reference speed $=1000 \mathrm{rpm}$ and Load Torque $T_{L}=0 \mathrm{Nm}$

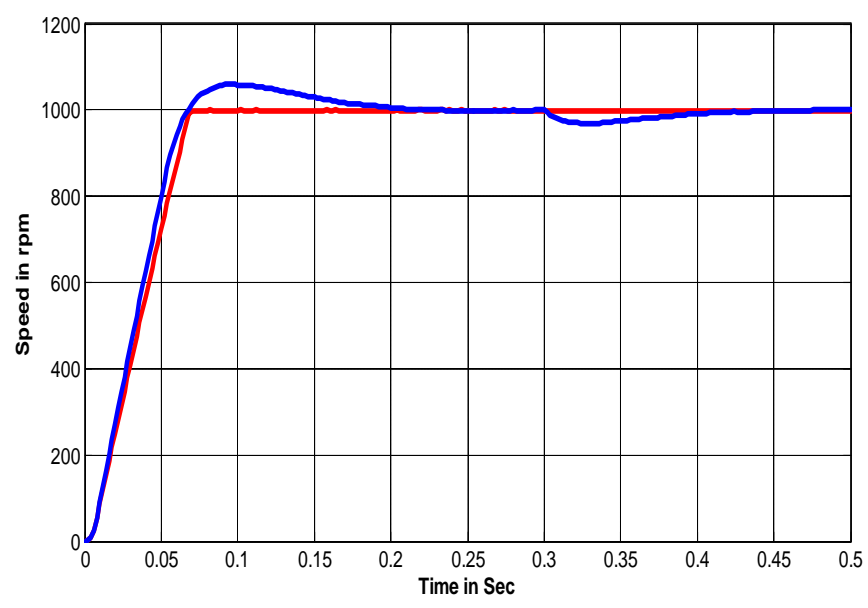

Figure 5 Comparison of speed Regulation of Induction motor using PI and ANFIS controllers based DTC for reference speed $=1000 \mathrm{rpm}$ and Load Torque $T_{L}=30 \mathrm{Nm}$.

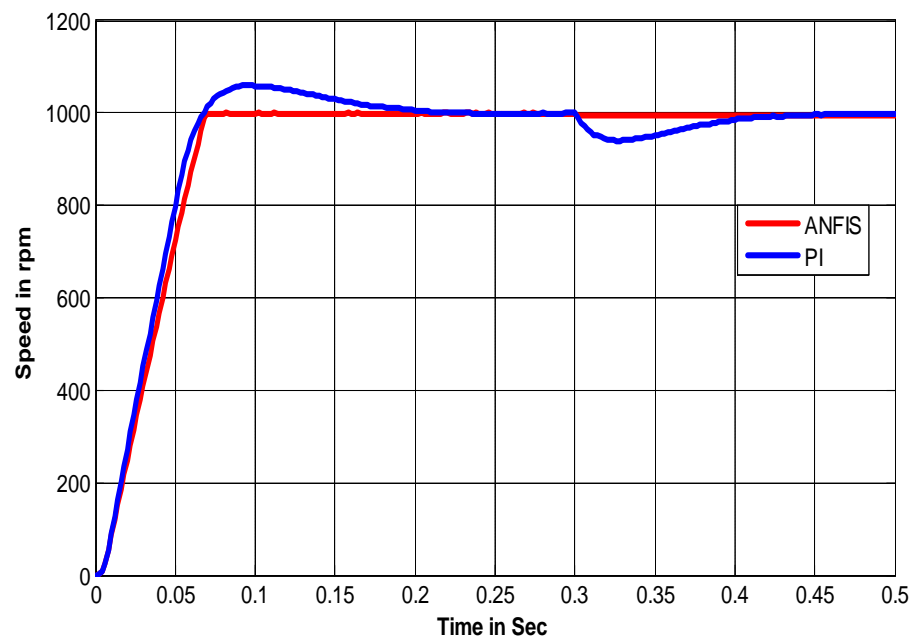

Figure 6 Comparison of speed Regulation of Induction motor using PI and ANFIS controllers based DTC for reference speed $=1000 \mathrm{rpm}$ and Load Torque $T_{L}=60 \mathrm{Nm}$. 


\section{International Journal of Science and Research (IJSR) \\ ISSN (Online): 2319-7064}

Index Copernicus Value (2013): 6.14 | Impact Factor (2014): 5.611

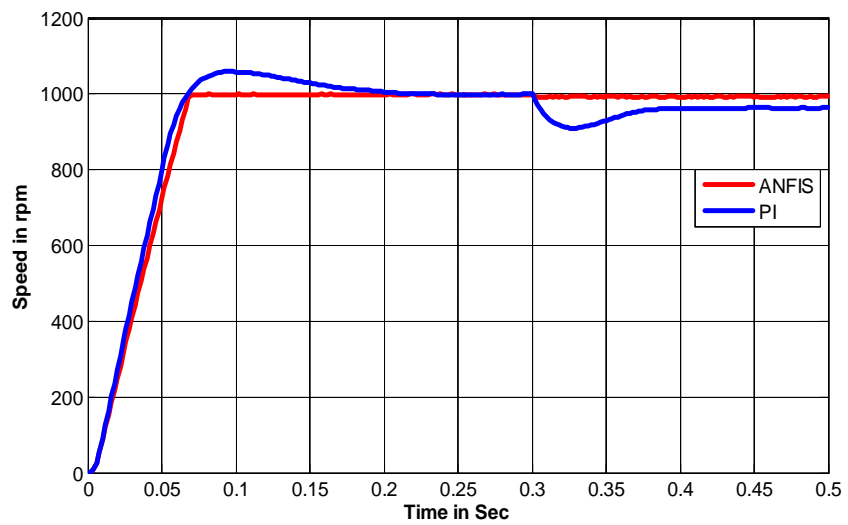

Figure 7 Comparison of speed Regulation of Induction motor using PI and ANFIS contr ollers based DTC for reference speed $=1000 \mathrm{rpm}$ and Load Torque $\mathrm{T}_{\mathrm{L}}=90 \mathrm{Nm}$.

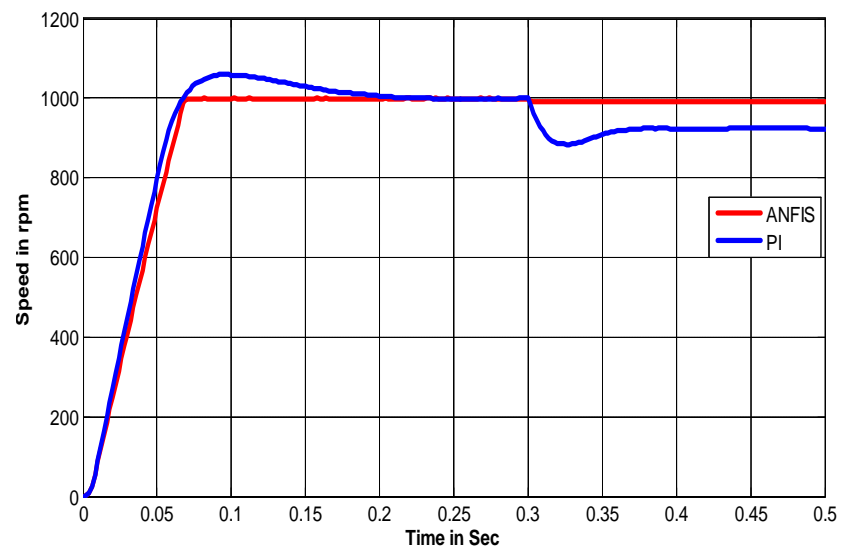

Figure 8 Comparison of speed Regulation of Induction motor using PI and ANFIS controllers based DTC for reference speed $=1000 \mathrm{rpm}$ and Load Torque $T_{L}=120 \mathrm{Nm}$.

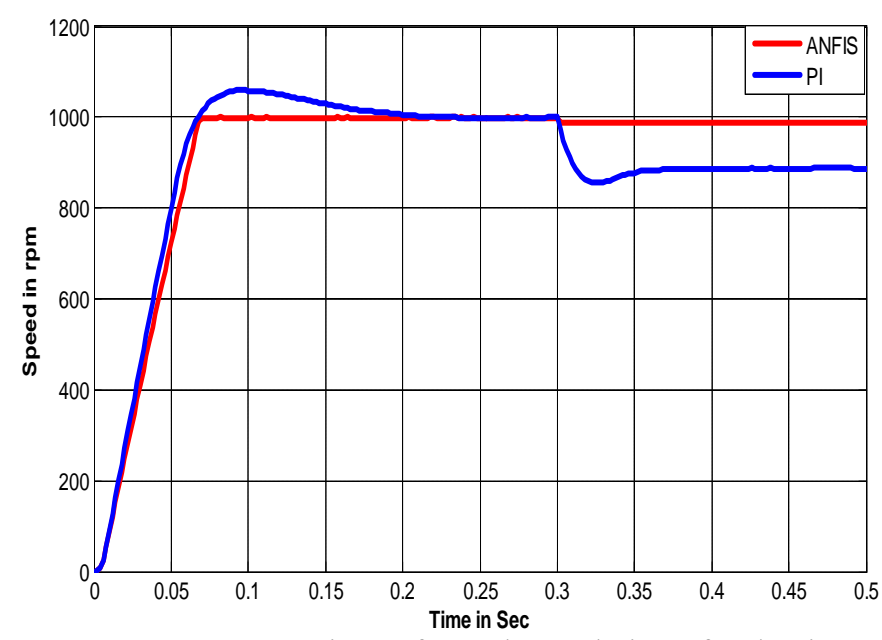

Figure 9 Comparison of speed Regulation of Induction motor using PI and ANFIS controllers based DTC for reference speed $=1000 \mathrm{rpm}$ and Load Torque $T_{L}=150 \mathrm{Nm}$

From the resultant waveforms for speed regulation of induction motor shown from figure (4) to figure (9), it is clearly observable that, for the no load condition (i.e. For $T_{L}$ $=0 \mathrm{Nm}$ ), the conventional PI controller based DTC controlled induction motor speed curve takes a big overshoot during the transient state and takes approximately $0.25 \mathrm{sec}$ to reach the specified reference speed of 1000rpm. While on the dynamic stability side with considering the load change situations generated at the $0.3 \mathrm{sec}$, it is found that, the speed of motor starts deviation from the reference speed of 1000 rpm, propostional to the amount of load used. For the highest load used here which is $150 \mathrm{Nm}$ the deviation obtained is approximately $130 \mathrm{rpm}$ which is very high. In addition to this for high load situation the convention PI controller based

DTC even not able to provide reduction in this difference after occurrence of the load.

\section{Result and Discussion}

On the same plots the results obtained for the proposed ANFIS based DTC controller, deploys that the developed ANFIS controller based DTC strategy for speed regulation of induction motor, is able to provide highly efficient speed regulation in transient as well as dynamic state operation. It is clearly evident from the comparative results plots that the proposed controller efficiently reaches to specified reference speed of $1000 \mathrm{rpm}$ within $0.06 \mathrm{sec}$ of settling time. The responses obtained for proposed controller is highly stable and approximately independent to the system load variations. Therefore the proposed ANFIS controller based DTC strategy for speed regulation of induction motor provides highly efficient and robust speed regulation under the variable load conditions. The settling time reduction by using the ANFIS controller based DTC is given by,

Reduction in settling time $=\{($ PI settling time - ANFIS settling time $) \div$ PI settling time $\} \times 100 \%$

$$
\begin{aligned}
\text { Reduction in settling time } & =\{(0.25-0.06) \div 0.06\} \times 100 \% \\
& =76.0 \%
\end{aligned}
$$

\section{Conclusion}

In this paper a new ANFIS based DTC controller for speed regulation of the induction motor has been proposed. The developed controller is specially designed to provide robust speed regulation of induction motor under highly variable load environment. After successful implementation of the proposed controller in MATLAB Simulink 2012(b), a complete performance evaluation of conventional PI controller based DTC and proposed control strategy for speed control of induction motor has been analyzed in detail. During the performance evaluation the main attention is given to obtain the capability of conventional PI controller based DTC and proposed controller, to handle the variations in the load.

After the complete comparative analysis among the proposed ANFIS based DTC and conventional DTC based speed regulation of induction motor under highly variable load conditions, it is found that, the speed regulation capability of the proposed technique is very robust and efficient as compare to conventional one. In addition to this it is also found that, the proposed speed regulation strategy not only provides regulated speed in the transient and dynamic state, but takes $76.0 \%$ less settling time as compare to conventional PI controller based DTC technique. 


\section{International Journal of Science and Research (IJSR) \\ ISSN (Online): 2319-7064}

Index Copernicus Value (2013): 6.14 | Impact Factor (2014): 5.611

\section{References}

[1] D. Casadei, G. Serra, A. Tani, L. Zarri, "Direct torque control for induction machines: a technology status Review, IEEE Workshop on Electrical Machines Design Control and Diagnosis, WEMDCD 2013, pp. 117-129, Paris, France, 11-12 Mar. (2013).

[2] I. Takahashi, Y. Ohmori, "High-performance direct torque controlof an induction motor", J. sci. IEEE Trans. on Industry Applications, vol. 25, pp. 257-264, Mar./Apr. (1989).

[3] M. Depenbrock, "Direct self-control (DSC) of inverterfed induction machine, J. sci. IEEE Trans. on Power Electronics, vol. 3,pp. 420-429, Oct. (1988).

[4] P. Vas, "Sensor less vector and direct torque control", Clarendon Press, (1998)..

[5] J. Ben Alaya, A. Khedher, M.F. Mimouni, "Speedsensor less DFIG wind drive based on DTC using sliding mode rotor flux observer", J. sci. International Journal of Renewable Energy Research, IJRER,vol. 2, no. 4, pp. 736-745, (2012).

[6] B. Mokhtari, A. Ameur, L. Mokrani, B. Azoui, M. F. Benkhoris,"DTC applied to optimize solar panel efficiency", in proc. of 5th IEEE Int. conf. on Industrial Electronics, pp. 1123-1127, IECON2009, Porto, Portugal, 3-5 Nov. (2009).

[7] J. H. Leong, Z. Q. Zhu, “Acoustic Noise and Vibration of Direct-Torque-Controlled Permanent Magnet Brushless DC Drives, in proc. of 6th IET Int.conf. on Power Electronics, Machines and Drives, PEMD 2012, pp.1-6, Brighton, UK, 27-29 March (2012).

[8] Y. Zhang, J. Zhu, "Direct torque control of permanent magnet synchronous motor with reduced torque ripple and commutation frequency", J. sci. IEEE Trans. Power Electronics, vol. 26, no. 1, pp.235-248, Jan. (2011).

[9] B. EI Badsi, B. Bouzidi, A. Masmoudi, "BusClamping-Based DTC: An Attempt to Reduce Harmonic Distortion and Switching Losses", J. sci. IEEE Trans. Power Electronics, vol. 60, no. 3, pp.873884, Mar. (2013).

[10] A. Arias, J. L. Romeral, and E. Aldabas, "Fuzzy logic direct torque control," in Proc. IEEE ISIE, 2000, vol. 1, pp. 253-258.

[11] D. Seyoum, M. F. Rahman, and C. Grantham, "Simplified flux estimation for control application in induction machines," in IEMDC'03, 2003, vol. 2, pp. 691-695.

[12] Yuedou Pan; Yihai Zhang; Zhe Wang, [1] "A novel variable domain adaptive fuzzy control of direct torque control for induction motor based on space vector control," Fuzzy Systems and Knowledge Discovery (FSKD), Seventh International Conference on, vol.2, pp.649,644, 10-12 Aug. 2010.

\section{Author Profile}

Yagya Bharti Goswami is pursuing M. Tech. (Electrical Devices and Power System), Electrical and Electronics Engineering Department, Disha Institute of Management and Technology, Raipur, (492001), Chhattisgarh, India.

S. M. Deshmukh is Head of the Department, Electrical And Electronics Engineering Department,
Disha Institute of Management And Technology, Raipur, (492001), Chhattisgarh, India. 